\title{
Pleuropericardial Compromise Associated With Graves' Disease: A Systematic Review
}

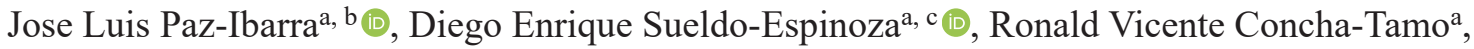 \\ Vladimir Zamame-Ramirez ${ }^{\text {a }}$, Victor Velasquez-Rimachid, e ${ }^{(0)}$, \\ Marcio Jose Concepcion-Zavaleta ${ }^{\mathrm{f}} \mathrm{g}(\mathbb{0}$
}

\begin{abstract}
Graves' disease (GD) is the main cause of hyperthyroidism. Cardiovascular complications of GD may have a delayed onset, accompanied by pericardial and pleural inflammation or inflammatory effusions. Pleuropericardial compromise (PPC) associated with GD is a rare disorder. It is postulated that the pathophysiology may involve an interaction between antithyroid antibodies and pericardium. Currently, there is no guideline for the treatment of GD-induced serositis. We conducted a systematic review to compare similar PPCs in GD reports. This article aimed to summarize the information to understand physiopathology and propose preliminary management. A total of 14 articles describing 16 cases of serositis induced by GD were selected. The characteristics of the pleural and pericardial fluid express the inflammatory nature of GD and facilitate the diagnosis. Imaging methods, mainly ultrasound (US), chest $\mathrm{X}$-ray, and computed tomography (CT), contribute to the diagnosis of PPC. Treatment of GD could be the cornerstone in the management of this entity, adding radioactive iodine as a definitive therapy if the patient does not reach a euthyroid state with antithyroid drugs.
\end{abstract}

Keywords: Graves' disease; Pleurisy; Pericarditis; Antithyroid agents

\section{Introduction}

Graves' disease (GD) is an autoimmune disease characterized

Manuscript submitted January 2, 2022, accepted January 28, 2022

Published online February 15, 2022

${ }^{a}$ Facultad de Medicina, Universidad Nacional Mayor de San Marcos, Lima, Peru ${ }^{b}$ Division of Endocrinology, Hospital Edgardo Rebagliati Martins, Lima, Peru 'Sociedad Cientifica de San Fernando, Lima, Peru

dRed de Eficacia Clinica y Sanitaria, REDECS, Libra, Los Olivos 15301, Lima, Peru

'Grupo de Investigacion Neurociencia, Efectividad Clinica y Salud Publica, Universidad Cientifica del Sur, Lima, Peru

fDivision of Endocrinology, Hospital Geriatrico San Jose, Lima, Peru

gCorresponding Author: Marcio Jose Concepcion-Zavaleta, Division of Endocrinology, Hospital Geriatrico San Jose, Lima, Peru.

Email: marcio.concepcion@unmsm.edu.pe

doi: https://doi.org/10.14740/jem790 by an increase in the serum levels of thyroid hormones due to the presence of autoantibodies against the thyroid-stimulating hormone (TSH) receptor, which increases the synthesis and release of thyroid hormones and glandular growth [1]. GD accounts for $70-80 \%$ of patients with hyperthyroidism in iodinesufficient countries, which has a worldwide prevalence close to $1 \%[2]$.

The main symptoms of GD are weight loss, irritability, heat intolerance, diarrhea, muscle weakness, sweating, tachycardia, systolic hypertension, tremor, goiter, and others. In addition, orbitopathy and dermopathy are observed in GD [3]. Orbitopathy accounts for $25-30 \%$ of patients with GD [4].

The inflammation accompanied by effusion of different serous membranes, mainly the pericardium and pleura, is usually associated with primary neoplasms or metastases, infections, autoimmune diseases, endocrine-metabolic disorders, and others $[5,6]$. GD has been rarely proposed in the literature as a trigger of pleuropericardial compromise (PPC). A clear pathophysiological linkage between both entities has not been identified. However, it is proposed that, similar to orbitopathy, autoantibodies involved in GD initiate an inflammatory process with the pericardium and pleura [4-7]. The diagnosis of PPC in GD is difficult usually because of exclusion due to its rare presentation. The American Thyroid Association (ATA) recommends three options for GD treatment, namely, antithyroid drugs (ATDs), radioactive iodine (RAI), and thyroidectomy [8].

The most common adverse event after therapy with RAI is hypothyroidism [8]. Other side effects include thyroiditis, orbitopathy, and malignancies [9].

Currently, there is no guideline for the treatment of GDinduced serositis. However, the management of GD as an underlying disease is paramount in those cases, adding colchicine, nonsteroidal inflammatory drugs, ASA, or corticoids to the management of pericarditis [10].

The present study aimed to explore initial clinical manifestations, the diagnostic approach, and the outcomes of the treatment in patients with PPC associated with GD, through a systematic review of case reports.

\section{Materials and Methods}

This is a systematic review study that aimed to identify all case 
reports related to GD-induced pericarditis or pleuritis (with or without effusion). We followed the Preferred Reporting Items for Systematic Reviews and Meta-Analyses [11] reporting guidelines for the systematic review and the CARE [12] guidelines for case reports.

\section{Systematic search}

The bibliographic research was designed by one autor (VVR). We searched the following electronic bibliographic databases via the Ovid interface from inception to January 2022: LILACS, MEDLINE, and Scopus. We considered studies published in all languages and developed the search strategy in consultation with a medical librarian and clinical experts from our institution. The following search terms were used in different combinations using Boolean search operators and search field tags to retrieve the articles: "Graves' disease," "hyperthyroidism," "polyserositis," "pericarditis," "pleurisy," "pericardial effusion," and "pleural effusion." We describe the complete search strategy here (Supplementary Material 1, www.jofem.org). We did not use any filter related to age as GD can affect both adults and children. In addition, we did not use methodological filters because of our expectations of recollecting all relevant data about this uncommon presentation. We did not hand-search the reference lists of the included articles to further identify relevant articles.

\section{Study selection}

We included case reports and case series of studies of patients diagnosed with GD with pleural or pericardial compromise. The requirement for acceptance was the inflammation of the serosa or an inflammatory effusion in a patient with a confirmed GD diagnosis. Moreover, we did not include conference proceedings and congress abstracts.

Two review authors (DSE and VZR) independently excluded studies that were not related to GD with pleural or pericardial inflammation or effusion because of the titles and abstracts identified by the search strategy. These authors retrieved the full text of relevant articles and independently tested them for inclusion. A third and fourth authors (JPI and MCZ) acted as arbiters in case of discrepancies between the two review authors (DSE and VZR) with regard to study inclusion. We created a flowchart illustrating our search process, including the reasons for exclusions. We did not include reports from the bibliographic references of the selected studies.

\section{Quality assessment}

We used the tool proposed by Murad et al [13]. This tool evaluated the methodological quality of case reports/series, assessing eight questions about four domains. Since our systematic review did not focus on cases of adverse events, we selected only six questions for our assessment: 1) selection (a: Does the patient(s) represent(s) the whole experience of the investigator (center) or is the selection method unclear to the extent that other patients with similar presentations may not have been reported?); 2) ascertainment (b: Was the exposure adequately ascertained? c: Was the outcome adequately ascertained?); 3) causality (d: Were other alternative causes that may explain the observation ruled out? e: Was follow-up long enough for prognosis outcomes to occur?); and 4) reporting (f: Is the case described with sufficient details to allow other investigators to replicate the research or to allow practitioners to make inferences related to their own practice?). As suggested by the authors, we summed up the scores of the binary responses in an aggregate score (six points at maximum) and defined equal or less than three as a low-quality study.

\section{Data extraction and narrative synthesis}

Two authors (DSE and VZR) independently evaluated the identified articles for inclusion. The same two review authors extracted the following data: 1) name of the author; 2) age and sex of the patient; 3) immunological signs; 4) etiology; 5) presence of cardiac tamponade; 6) characteristics of the effusion (for pleural or pericardial); 7) management of the effusion; 8) treatment of GD; 9) additional treatment; 10) follow-up period; and 11) outcome.

We performed a narrative approach to synthesizing the included studies. A narrative synthesis is an approach to the systematic review and synthesis of findings from multiple studies; it depends primarily on the use of words and text to explain and summarize the findings. We employed a four-stage process based on previous guidelines by Popay et al [14] (2006): 1) developing a theory of how/why the association can be justified (pathophysiological and clinical plausibility); 2) developing a preliminary list of synthesis categories (age, immunological signs, cardiac tamponade, pleural or pericardial inflammation, characteristics of the effusion, management of effusion, GD treatment, additional treatment, follow-up, and outcome); 3) exploring the relationships between and within the included cases and presenting them in a summary table; and 4) proposing diagnosis criteria based on the most critical and frequent characteristics (clinical manifestations, imaging, and electrocardiogram (ECG)) identified in the synthesis categories.

\section{Results}

\section{Systematic search}

This review was a retrospective assessment of 14 published research articles, with 15 cases in total. The age range of the patients was 17 - 76 years; $40 \%(6 / 15)$ of the patients were female, who were referred to or seeking medical assistance for PPC in GD.

We included 42 reports for analysis (Fig. 1) and considered for analysis each case with a confirmed diagnosis of GD being the cause of pleura or pericardium with or without subsequent effusion or GD as a cause of inflammatory effusion. After reviewing the complete text, we excluded 28 studies as they did not include aim cases. Eight cases were considered as 

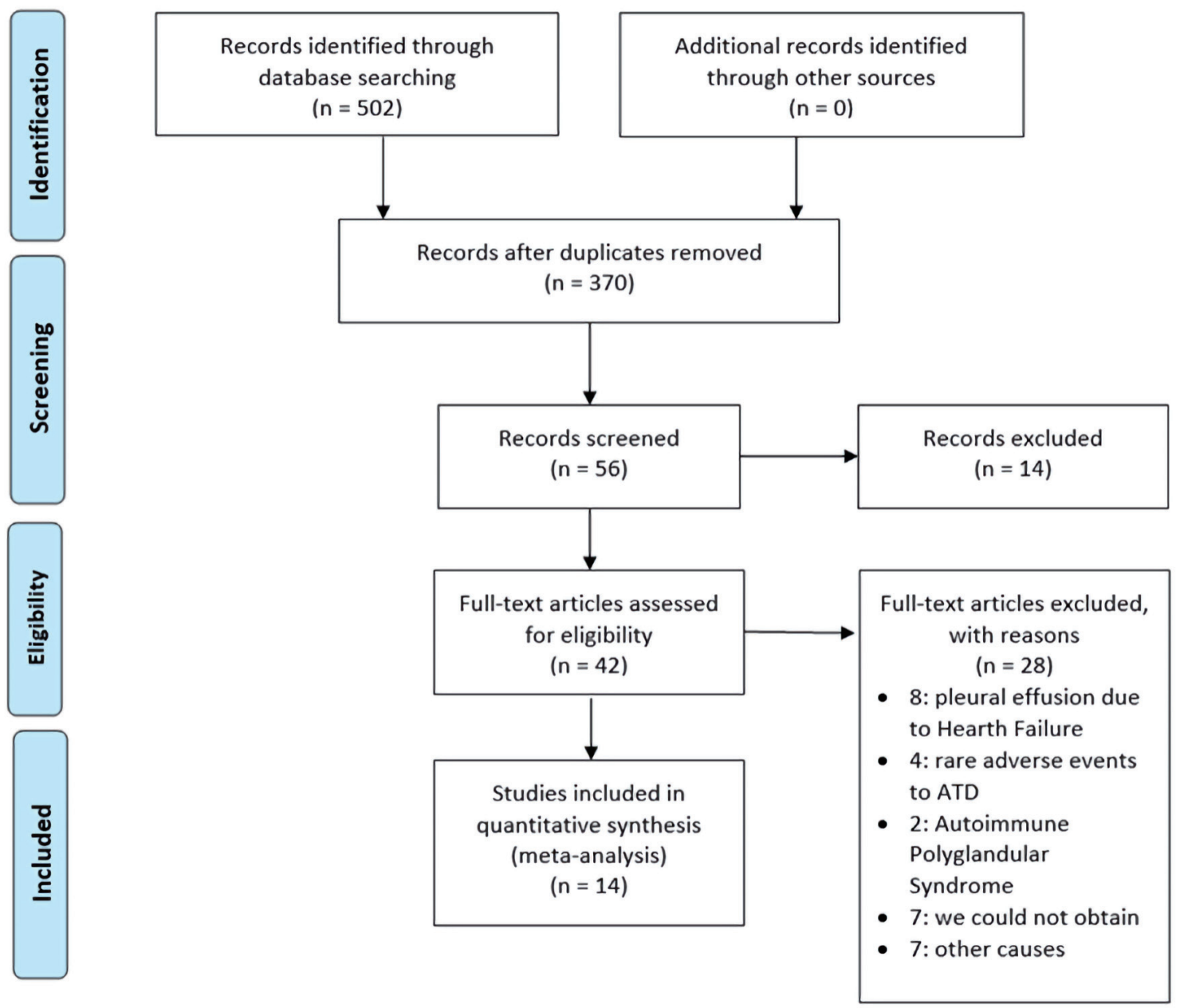

Figure 1. Flow diagram of screening and selection of articles adapted from the PRISMA. PRISMA: Preferred Reporting Items for Systematic Reviews and Meta-Analyses; ATD: antithyroid drug.

the consequence of heart failure [15-20]. Four cases consisted of pleural effusions as a rare adverse reaction due to ATD intake [21-24]. Two cases were associated with polyglandular autoimmune syndromes $[25,26]$. Three cases consisted of pericarditis in a patient with hyperthyroidism, but the pericarditis was attributed to viral infections [27]. The etiology of the three cases were as follows: hashitoxicosis [28], obstruction of thoracic duct [29], and peripartum heart failure [30]. Seven reports were inaccessible [31-37]. One study was excluded because it was a case of hyperthyroidism without a specific cause mentioned [38]. Fourteen studies, including 15 patients in total, were included in the qualitative review (Table 1) [7, 39-51]. In addition, we registered the diagnostic features of PPC (Table 2) [7, 39-51].

\section{Quality of included studies}

The average score of the quality scale was $4.13(3-6)$. One study reached a perfect score (six points). The experience of the investigator and the follow-up were the sections with more missing information (Table 3) [7, 39-51]. A total of 13 cases reported follow-up data (four of them reported 6 months or more).

\section{Narrative synthesis}

Fourteen studies, including 15 patients in total (Table 1) [7, 39-51] were included in the qualitative review, being cases of serositis associated with GD [7, 39-51]. The mean age of the patients in the studies was $47.2 \pm 18.7$ years at the time of diagnosis. In addition, six patients were female [7, 42, 44, 48, 49], accounting for $40 \%$ of the sample. Regarding clinical features that implied immunological features, orbitopathy was present in two patients [39, 45] and goiter in eight [39, 40, 42-44, 4648]; dermopathy was not detected in any of the patients.

Referring to PPC, 10 cases consisted of pericarditis alone $[39,42,44-48,49-51]$, one of pleuritis alone [41], and one of both pericarditis and pleuritis [7]. Three cases did not have a diagnosis of pleurisy or pericarditis but developed an isolated effusion [40, 43, 48]. Effusion with or without serosity is developed in nine patients [7, 40-44, 46, 48, 50], of whom 


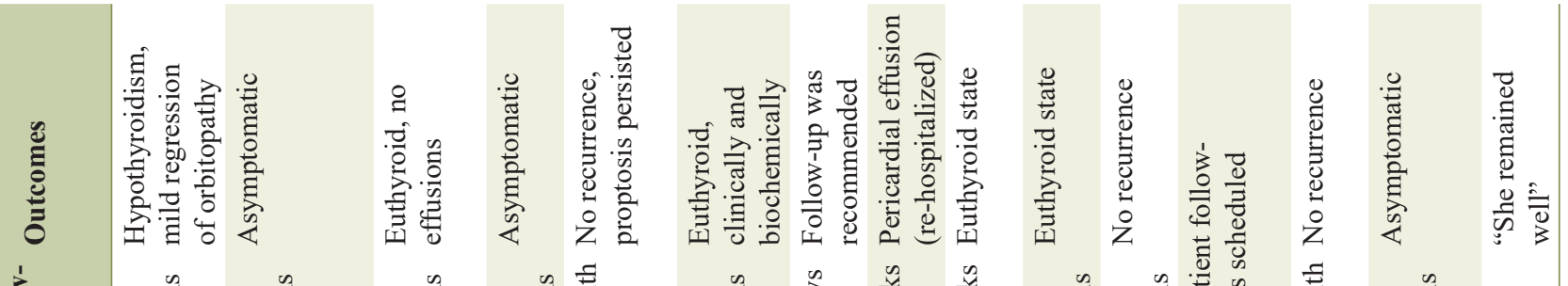

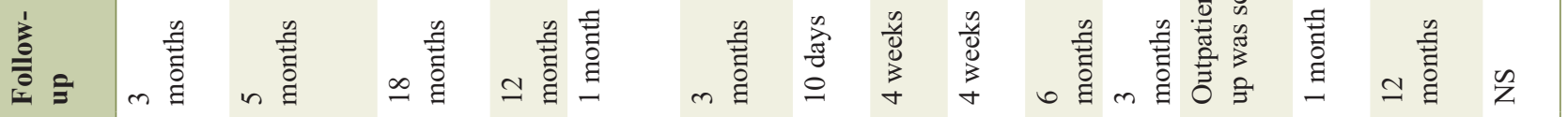

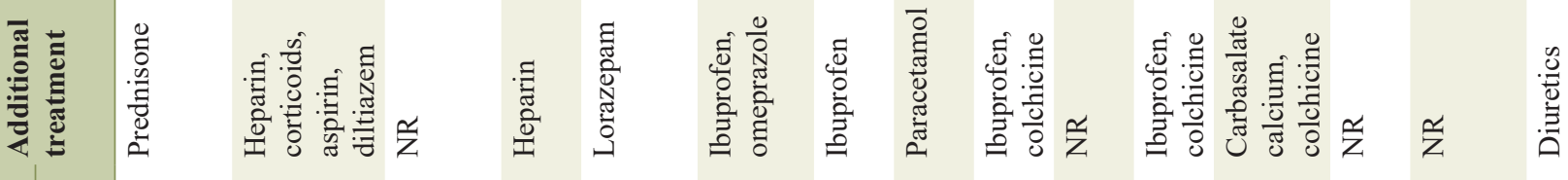


Table 2. Diagnostic Features of Pleuropericardial Compromise (PPC)

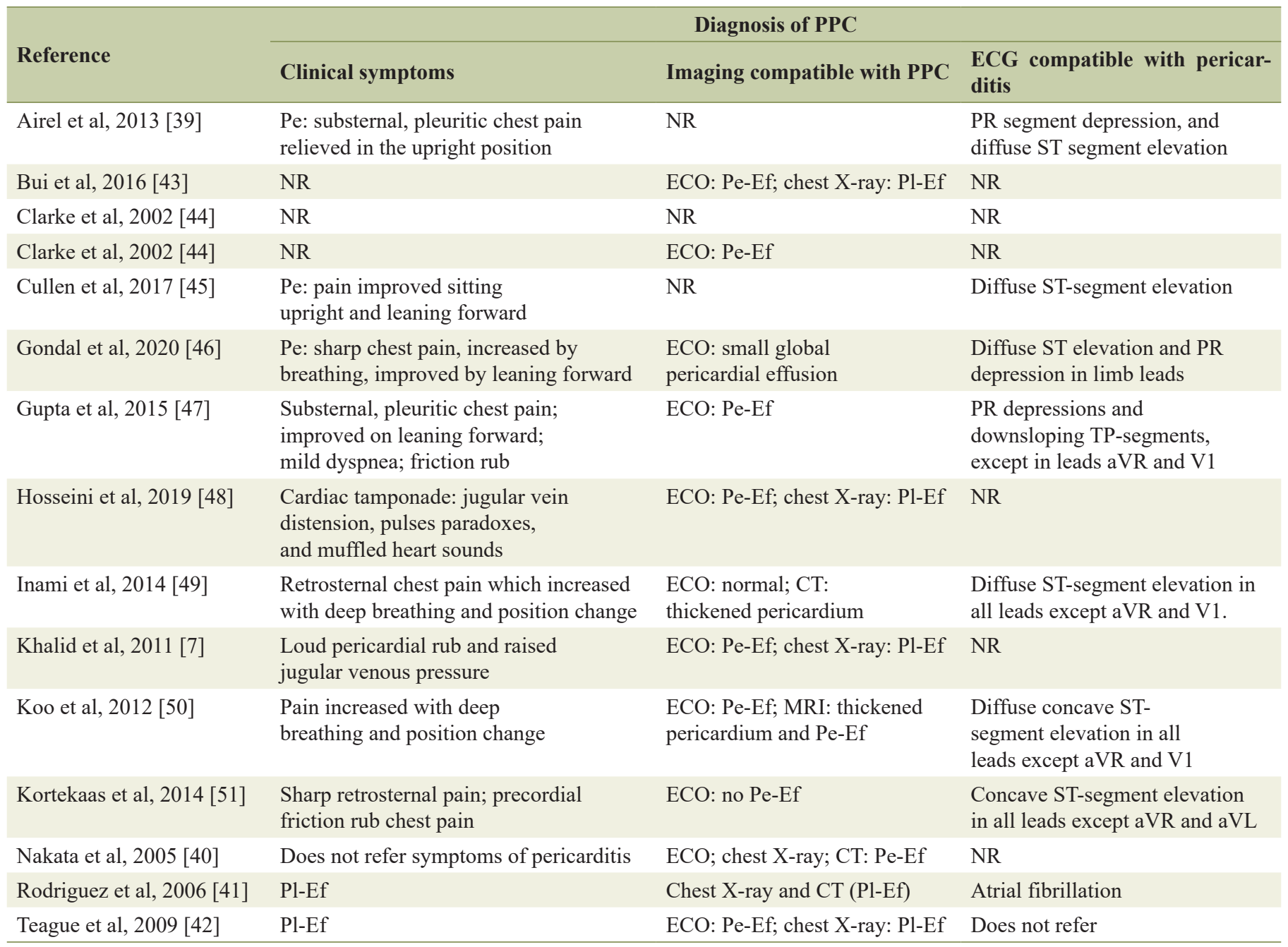

Pe: pericarditis; ECG: electrocardiogram; CT: computed tomography; ECO: echocardiography; MRI: magnetic resonance imaging; Pe-Ef: Pericardial effusion; PI-Ef: Pleural effusion; NR: does not refer.

five were cases of pleuropericardial effusions [7, 42-44, 48]. Regarding the cytochemical analysis, pericardial effusion developed in nine patients, of whom were cases of exudative effusion $[40,42,43,48]$ and five of uncategorized effusion [7, $44,46,50]$. On the other hand, pleural effusion developed in six patients, of whom one was a case of transudative effusion [43], two were exudative effusion [43], and three were uncategorized effusion $[42,44,48]$.

Clinically, there were different manifestations related to PPC. Pericarditis was referred to clinically in eight reports [7, 39, 45-51], being chest sharp pain, leaning forward the most frequent symptom. Symptoms suggestive of pleural effusion occurred in two reports $[41,42]$, whereas cardiac tamponade symptoms were referred to in one report [48]. Four case reports did not report symptoms suggestive of PPC [40, 43, 44].

ECG revealed manifestations of pericarditis in seven reports [39, 45-50], whereas four reports (five patients in total) did not mention any sign [7, 42-44]. Four reports described atrial fibrillation $[41,43,47,48]$, and six described sinus rhythm [39, 40, 46, 48, 50, 51].

The reviewed case reports mentioned different imaging techniques for diagnosing any type of PPC. Echocardiography was the most used method, as described in 12 reports [7, 39$44,46-48,50,51]$. Other methods of imaging were chest X-ray in six patients [7, 40-43, 48], computed tomography (CT) in four $[39-41,49]$, and magnetic resonance imaging (MRI) in one [50]; two reports did not mention any technique [44, 45]. The results of this imaging method for diagnosis are presented briefly in Table 2 [7, 39-51], in addition to the main symptoms and ECG characteristics.

With regard to treatment, 13 patients were prescribed with ATD [7, 39, 40, 42-47, 49-51], such as carbimazole, methimazole, propylthiouracil; 10 combined plus a $\beta$ antagonist drug $[7,39,42,44-47,49,51]$. Three patients received RAI, two of them received RAI in combination with ATD $[39,44]$, and the other received RAI alone [41]. Thyroidectomy was not prescribed to any patient. One patient did not receive any therapeutic indication for GD [48]. 
Table 3. Quality Assessment of Included Papers

\begin{tabular}{|c|c|c|c|c|c|c|c|}
\hline \multirow[b]{2}{*}{ Study } & \multirow[b]{2}{*}{$\begin{array}{l}\text { Selection } \\
\text { a. Does the patient(s) } \\
\text { represent(s) the whole } \\
\text { experience of the inves- } \\
\text { tigator (center) or is the } \\
\text { selection method unclear } \\
\text { to the extent that other } \\
\text { patients with similar } \\
\text { presentation may not } \\
\text { have been reported? }\end{array}$} & \multicolumn{2}{|c|}{ Ascertainment } & \multicolumn{2}{|c|}{ Causality } & \multirow[b]{2}{*}{$\begin{array}{l}\quad \text { Reporting } \\
\text { f. Is the case } \\
\text { described with suffi- } \\
\text { cient details to allow } \\
\text { other investigators } \\
\text { to replicate the } \\
\text { research or to allow } \\
\text { practitioners make } \\
\text { inferences related to } \\
\text { their own practice? }\end{array}$} & \multirow[b]{2}{*}{$\begin{array}{l}\text { Total } \\
\text { score }\end{array}$} \\
\hline & & $\begin{array}{l}\text { b. Was the } \\
\text { exposure } \\
\text { adequately } \\
\text { ascer- } \\
\text { tained? }\end{array}$ & $\begin{array}{l}\text { c. Was } \\
\text { the out- } \\
\text { come } \\
\text { ade- } \\
\text { quately } \\
\text { ascer- } \\
\text { tained? }\end{array}$ & $\begin{array}{l}\text { d. Were } \\
\text { other } \\
\text { alterna- } \\
\text { tive causes } \\
\text { that may } \\
\text { explain the } \\
\text { observation } \\
\text { ruled out? }\end{array}$ & $\begin{array}{l}\text { e. Was } \\
\text { follow- } \\
\text { up long } \\
\text { enough } \\
\text { for } \\
\text { prognosis } \\
\text { outcomes } \\
\text { to occur? }\end{array}$ & & \\
\hline Airel et al, 2013 [39] & Yes & Yes & Yes & No & No & Yes & 4 \\
\hline Bui et al, 2016 [43] & Yes & Yes & Yes & Yes & No & Yes & 5 \\
\hline Clarke et al, 2002 [44] & No & Yes & Yes & Yes & Yes & No & 4 \\
\hline Clarke et al, 2002 [44] & No & Yes & Yes & Yes & Yes & No & 4 \\
\hline Hosseini et al, 2019 [48] & Yes & Yes & Yes & Yes & No & Yes & 5 \\
\hline Inami et al, 2014 [49] & No & Yes & Yes & Yes & No & Yes & 4 \\
\hline Khalid et al, 2011 [7] & No & Yes & Yes & Yes & Yes & Yes & 5 \\
\hline Koo et al, 2012 [50] & Yes & Yes & Yes & Yes & No & Yes & 5 \\
\hline Kortekaas et al, 2014 [51] & No & Yes & No & Yes & No & Yes & 3 \\
\hline Nakata et al, 2005 [40] & No & Yes & Yes & Yes & No & Yes & 4 \\
\hline Rodriguez et al, 2006 [41] & Yes & Yes & Yes & Yes & Yes & Yes & 6 \\
\hline Teague et al, 2009 [42] & Yes & Yes & No & No & No & Yes & 3 \\
\hline
\end{tabular}

Surgical management was performed as follows: five patients underwent pericardiocentesis [40, 42-44, 48], and two patients underwent thoracentesis $[41,43]$.

The follow-up time was variable, with a median of 3 months, a maximum of 18 months [44], and a minimum of 10 days [47]. Twelve patients successfully responded, without recurrence $[7,39-46,49,50]$. One patient, who had been prescribed with ATD and RAI, recovered but had a regression of orbitopathy [39]. Other patients recovered but exhibited persistence of lid lag and proptosis [45]. Two patients seemed to recover; however, the follow-up period was short, only a few days, so their outcome was uncertain $[47,51]$. One patient, who did not receive any antithyroid treatment, had a recurrent pericardial effusion 4 weeks after discharge [48].

\section{Discussion}

When a patient attends to the hospital presenting signs of thyrotoxicosis and manifestations of pleural or pericardial compromise, the clinical team must do some investigations. Firstly, hyperthyroidism must be evaluated with thyroid hormones (T3 and T4) and TSH $[1,8]$. Then, physicians have to determine the cause of hyperthyroidism. GD is the main cause; and can be diagnosed solely with signs of orbitopathy or dermopathy, antithyroid receptor antibody, or RAI-uptake [8]. Meanwhile, in patients with suspected hyperthyroidism and pleuropericardial effusion, it is important to exclude differential diagnosis such as neoplasms [7], tuberculosis [52], rheumatologic and autoimmune diseases $[53,54]$. Excluding the other causes makes the association between PPC and GD possible [51]. This criterion is reinforced due to recovery of the effusion and no recurrence following resolution of hyperthyroidism [10]. Pleural and pericardial inflammation accompanied by effusion in a patient with hyperthyroidism is rare. It is postulated that the pathophysiology may involve an interaction between antithyroid antibodies and pericardium, similar to orbitopathy and dermopathy [38, 43, 46].

Most cases reported typical signs of pericarditis, such as sharp chest pain [7, 39, 45-47, 49-51]. The most common method for evaluating pericardial effusion was ultrasound (US) $[7,40,42-44,46-48,50]$, whereas chest X-ray was the commonly used method for pleural effusions [7, 41-43, 48]. Both methods served to identify effusions in our patients, whereas $\mathrm{CT}$ was added to improve imaging quality. CT was used to evaluate pleural [41] and pericardial [40] effusion in all cases reported in the literature. Only one report employed MRI to observe pericardial effusion and thickening [50]; however, we did not use this method. Because of the frequency used and its ability to detect pericardial effusion, US might be the main im- 
aging method. However, chest X-ray and CT should evaluate the lungs and the mediastinum to explore PPC, like the present and previous reports.

Regarding PPC, 11 patients had pericarditis alone [39, 42-47, 49-51] and one had pleuritis alone [41], whereas three others did not have inflammation but had effusions, which were exudative $[40,44,48]$. Only one patient had pleuropericarditis [7]. The pericardial effusion was exudative in four of the nine cases (the other five were not identified) [40, 42, 43, 48]. Pleural effusion was transudate in one [43] of the seven cases; the additional two were cases of exudative effusion [7, 41], whereas the other four were cases of uncategorized effusion.

Regarding the treatment, $86.67 \%$ of patients in the reviewed cases received ATD [7, 39, 40, 42-47, 49-51]. Most of them received combined therapy ATD plus $\beta$ antagonist [7, $39,42,44-47,49,51]$. RAI was used in $20 \%$ of patients [39, $41,44]$ ATD is recommended in a high likelihood of remission, such as mild disease or low antibody titers. RAI is recommended for contraindications to ATD or when the patient cannot reach a euthyroid state with drugs, with a single dose of $10-15 \mathrm{mCi}$. The contraindications for RAI are coexisting thyroid malignancy and pregnancy. RAI is preferred in the USA, whereas ATD is commonly used as first-line treatment in Europe, Japan, and Latin America [8]. Thyroidectomy is other alternative of treatment, which is most preferred to GD with coexisting active nodules, malignancy, or hyperparathyroidism [8]. Other types of medical therapies that have been used to treat hyperthyroidism [8] are lithium, cholestyramine, iodine, etc. The median time of follow-up was 6.5 months (from 10 days to 18 months) [44, 47]. Thirteen patients did not have a recurrence of effusions [7, 39-46, 49, 50]. Two did not have a conclusive outcome because the follow-up period was only a few days $[47,51]$. Recurrence was reported in one case [48] due to a lack of therapy for GD.

\section{Conclusions}

Cardiovascular complications of GD may have a delayed onset, accompanied by pericardial and pleural inflammation or inflammatory effusions. PPC associated with GD should be diagnosed discarding other more common differential diagnoses. The characteristics of the pleural and pericardial fluid express the inflammatory nature of GD and facilitate the diagnosis. Imaging methods, mainly US, chest X-ray, and CT, contribute to the diagnosis of PPC. The treatment of GD is the cornerstone of this entity.

\section{Supplementary Material}

Suppl 1. The complete search strategy.

\section{Acknowledgments}

None to declare.

\section{Financial Disclosure}

No funding to declare.

\section{Conflict of Interest}

None to declare.

\section{Author Contributions}

JPI conceived the study; JPI, DSE and VVR contributed to the development of methodology, VVR designed the bibliographic research; DSE, VZR and RC search articles for inclusion and critically evaluated the articles; JPI and MCZ extracted data from articles; JPI and MCZ solved discrepancies in the selection of articles; all authors participated in data analysis, drafting and final approval of the manuscript.

\section{Data Availability}

The authors declare that data supporting the findings of this study are available within the article.

\section{References}

1. De Leo S, Lee SY, Braverman LE. Hyperthyroidism. Lancet. 2016;388(10047):906-918.

2. Taylor PN, Albrecht D, Scholz A, Gutierrez-Buey G, Lazarus JH, Dayan CM, Okosieme OE. Global epidemiology of hyperthyroidism and hypothyroidism. Nat Rev Endocrinol. 2018;14(5):301-316.

3. Smith TJ, Hegedus L. Graves' Disease. N Engl J Med. 2016;375(16):1552-1565.

4. Bahn RS. Graves' ophthalmopathy. N Engl J Med. 2010; 362(8):726-738.

5. Losada I, Gonzalez-Moreno J, Roda N, Ventayol L, Borjas Y, Dominguez FJ, Fernandez-Baca V, et al. Polyserositis: a diagnostic challenge. Intern Med J. 2018;48(8):982987.

6. Levy PY, Corey R, Berger P, Habib G, Bonnet JL, Levy S, Messana T, et al. Etiologic diagnosis of 204 pericardial effusions. Medicine (Baltimore). 2003;82(6):385-391.

7. Khalid Y, Sulaiman R, Zahir R, Baskar V, Buch HN. An unusual complication in a patient with Graves' disease. N Z Med J. 2011;124(1341):69-71.

8. Ross DS, Burch HB, Cooper DS, Greenlee MC, Laurberg P, Maia AL, Rivkees SA, et al. 2016 American Thyroid Association Guidelines for diagnosis and management of hyperthyroidism and other causes of thyrotoxicosis. Thyroid. 2016;26(10):1343-1421.

9. Mumtaz M, Lin LS, Hui KC, Mohd Khir AS. Radioiodine I-131 for the therapy of graves' disease. Malays J Med Sci. 2009;16(1):25-33.

10. Schwier NC, O'Neal K. Pharmacotherapeutic manage- 
ment strategies for thyroid disease-induced pericarditis. Ann Pharmacother. 2020;54(5):486-495.

11. Page MJ, McKenzie JE, Bossuyt PM, Boutron I, Hoffmann TC, Mulrow CD, Shamseer L, et al. The PRISMA 2020 statement: an updated guideline for reporting systematic reviews. BMJ. 2021;372:n71.

12. Riley DS, Barber MS, Kienle GS, Aronson JK, von Schoen-Angerer T, Tugwell P, Kiene H, et al. CARE guidelines for case reports: explanation and elaboration document. J Clin Epidemiol. 2017;89:218-235.

13. Murad MH, Sultan S, Haffar S, Bazerbachi F. Methodological quality and synthesis of case series and case reports. BMJ Evid Based Med. 2018;23(2):60-63.

14. Popay J, Roberts H, Sowden A, Petticrew M, Arai L, Rodgers M, Britten N, et al. Guidance on the conduct of narrative synthesis in systematic reviews: a product from the ESRC methods programme. ESRC, Swindon. 2006.

15. Hsieh MH, Chen CC, Wang TY, Chang CT. Chylous ascites as a manifestation of thyrotoxic cardiomyopathy in a patient with untreated Graves' disease. Thyroid. 2010;20(6):653-655.

16. Kinoshita H, Yasuda M, Kaneko S, Usui R, Inoshita S, Furumoto Y, Maruyama Y, et al. Thyroid hormones, their carrier proteins, and thyroid antibodies in the pleural effusion of two patients with graves' disease-induced thyrotoxicosis. Endocr Res. 2010;35(4):183-187.

17. Moumen A, Meftah A, Benkacem M, El Masmoudi A, El Moussaoui S, Belmejdoub G. [Pericardial effusion: An unknown expression of Graves' disease]. Presse Med. 2014;43(10 Pt 1):1129-1133.

18. Ovadia S, Lysyy L, Zubkov T. Pericardial effusion as an expression of thyrotoxicosis. Tex Heart Inst J. 2007; 34(1):88-90.

19. Witczak JK, Ubaysekara N, Ravindran R, Rice S, Yousef Z, Premawardhana LD. Significant cardiac disease complicating Graves' disease in previously healthy young adults. Endocrinol Diabetes Metab Case Rep. 2020;2020:19-013.

20. van Zwieten PA. The rational for the use of A-Blockers in the treatment of congestive heart failure. Am J Geriatr Cardiol. 1992;1(3):57-61.

21. Cardona Attard CD, Gruppetta M, Vassallo J, Vella S. Carbimazole-induced exudative pleural effusions. BMJ Case Rep. 2016;2016:bcr2016215080.

22. Ferguson C, Bradley C, Kidney J. Carbimazole-induced eosinophilic pleural effusion. BMJ Case Rep. 2018;2018:bcr2018224701.

23. Khine LY, Kim DW, Olajide O, White C, Shweihat Y, Driscoll H. Methimazole-induced pleural effusion in the setting of Graves' disease. Case Rep Endocrinol. 2019;2019:5748938.

24. Martin Jimenez ML, Mellor-Pita S, Tutor-Ureta P. Pleural effusion associated to methimazole. Med Clin (Barc). 2018;151(6):e31-e32.

25. Fernandez Fernandez FJ, de la Fuente Aguado J, Perez Fernandez S, Hervas Abad E, Paramo Fernandez C. [Recurrent serositis as manifestation of autoimmune polyglandular syndrome type 2]. Rev Clin Esp. 2006;206(8):410.

26. Palmer WC, Kurklinsky A, Lane G, Ussavarungsi K,
Blackshear JL. Cardiac tamponade due to low-volume effusive constrictive pericarditis in a patient with uncontrolled type II autoimmune polyglandular syndrome. Acute Card Care. 2014;16(1):23-27.

27. Treusch JV, Jaffe HL. Hyperthyroidism associated with presumptive acute pericarditis; a report of three cases. Calif Med. 1958;89(3):217-221.

28. Lamari A, Dattilo G, Tulino D, Marte F, Patane S. Hashitoxicosis with pericardial effusion. Int J Cardiol. 2010;145(2):e77-e79.

29. Young Oh S, Hyun Kim B, Young Kim D, Min Lee $\mathrm{K}$, Jin Lee M, Su Kim S, Ho Kim J, et al. Chylothorax associated with substernal goiter in Graves' disease treated with radioactive iodine. Int J Endocrinol Metab. 2017;15(2):e41787.

30. Valko PC, McCarty DL. Peripartum cardiac failure in a woman with Graves' disease. Am J Emerg Med. 1992;10(1):46-49.

31. Algun E, Erkoc R, Kotan C, Guler N, Sahin I, Ayakta H, Uygan I, et al. Polyserositis as a rare component of polyglandular autoimmune syndrome type II. Int J Clin Pract. 2001;55(4):280-281.

32. Jochweds B, Keydana-Jedrzejewska B. [Pulmonary-pleuro-pericardial syndrome in the course of hyperthyroidism]. Pol Tyg Lek. 1969;24(18):685-686.

33. Kukla P, Bryniarski L, Bromblik A, Szczuka K, Kawecka-Jaszcz K. [Myopericarditis complicated with cardiogenic shock mimicking acute coronary syndrome with ST elevation in a patient with hyperthyroidism and diabetes mellitus]. Kardiol Pol. 2008;66(9):982-986; discussion 986.

34. Lin Y-J, Lai L-P, Chang T-C. Graves' disease combined with autoimmune pericarditis - A case report. Acta Cardiol Sin. 1997; 13(2):112-116.

35. Moreno JA, Larranaga JR, Lopez-Guerra N, Mendez MJ, Mosteiro M. [Occult thyrotoxicosis: a preventable cause of pleural effusion]. An Med Interna. 1995;12(5):256.

36. Szoko M, Mayer G, Simon G. [Untreated hyperthyroidism with severe cardiac complication in adolescence-a case study]. Orv Hetil. 2005;146(15):711-716.

37. Tourniaire J, Sassolas G, Touboul P, Lejeune H, Berger M. [Tamponade caused by subacute pericarditis in Basedow's disease]. Presse Med. 1983;12(32):1989-1990.

38. Sugar SJ. Pericarditis as a complication of thyrotoxicosis. Arch Intern Med. 1981;141(9):1242.

39. Airel PS, Steele MB, Lin AH, Seidensticker DF, Shwayhat AF. Pericarditis, thymic hyperplasia, and Graves' thyrotoxicosis: case report and review of the literature. Mil Med. 2013;178(7):e865-869.

40. Nakata A, Komiya R, Ieki Y, Yoshizawa H, Hirota S, Takazakura E. A patient with Graves' disease accompanied by bloody pericardial effusion. Intern Med. 2005;44(10):1064-1068.

41. Rodriguez-Flores E, Nonell-Gregori F, Miret-Mas C, Smithson-Amat A. [Graves-Basedow disease and pleural effusion]. Med Clin (Barc). 2006;126(2):76-77.

42. Teague E, O'Brien CJ, Campbell NP. Pericardial effusion and tamponade complicating treated graves' thyrotoxocosis. Ulster Med J. 2009;78(1):56-57. 
43. Bui PV, Zaveri SN, Pierce JR, Jr. Sanguineous pericardial effusion and cardiac tamponade in the setting of Graves' disease: report of a case and review of previously reported cases. Case Rep Med. 2016;2016:9653412.

44. Clarke NR, Banning AP, Gwilt DJ, Scott AR. Pericardial disease associated with Grave's thyrotoxicosis. QJM. 2002;95(3):188-189.

45. Cullen D, Munjal N, Chalal H, Ramgopal S, Tas E, Witchel S. Pericarditis as the Presenting Feature of Graves Disease in a Pediatric Patient. Pediatr Emerg Care. 2017;33(4):268-270.

46. Gondal M, Hussain A, Yousuf H, Haider Z. Double trouble - thyro-pericarditis: rare presentation of Graves' disease as pericarditis-a case report. Eur Heart J Case Rep. 2020;4(6):1-5.

47. Gupta P, Chhabra L, Hiendlmayr B, Spodick DH. Thyrotoxic pericarditis: An underappreciated phenomenon. Int J Cardiol. 2015; 198:32-33.

48. Hosseini SAA, Sarchahi Z, Shaermoghadam S, Ghodsi H. A case of pericardial effusion and cardiac tamponed with hyperthyroidism. Prensa Med Argent. 2019;105(2).

49. Inami T, Seino Y, Goda H, Okazaki H, Shirakabe A, Yamamoto M, Okajima F, et al. Acute pericarditis: unique comorbidity of thyrotoxic crisis with Graves' disease. Int J Cardiol. 2014;171(3):e129-130.

50. Koo EH, Kim SM, Park SM, Park JW, Kim EK, Lee GY, Chang SA, et al. Acute recurrent pericarditis accompanied by graves' disease. Korean Circ J. 2012;42(6):419422.

51. Kortekaas KA, van der Lienden B, Jong S, Riezebos R. Graves' disease as an uncommon cause of acute pericarditis. BMJ Case Rep. 2014;2014:bcr2013203342.

52. Herrera Gomez A, Granados Garcia M. Pericardic effusion. In: Herrera Gomez, eds. Manual of Oncology. Mexico: McGraw-Hill Interamericana; 2013; p. 229-233.

53. Fanlo P, Tiberio G. [Extrapulmonary tuberculosis]. An Sist Sanit Navar. 2007;30(Suppl 2):143-162.

54. Ansari A, Larson PH, Bates HD. Cardiovascular manifestations of systemic lupus erythematosus: current perspective. Prog Cardiovasc Dis. 1985;27(6):421-434. 